\title{
On the Usage of Sinhalese Differential Object Markers Object Marker /wa/ vs. Object Marker |tal
}

\author{
Kanduboda A, B. Prabath \\ Ritsumeikan University, Ritsumeikan International, Global Gateway Program, Japan
}

\begin{abstract}
Previous studies (Aisen, 2003; Kanduboda, 2011) on Sinhalese language have suggested that direct objects (i.e., accusative marked nouns) in active sentences can be marked by two distinctive case markers. In some sentences, accusative nouns can be denoted by the accusative case marker $/ w a /$. In other sentences, the same nouns can again be denoted by the dative case marker /ta/. However, the verbs required by these accusatives were not investigated in the previous studies. Thus, the present study further conducted an investigation to observe whether these two types of case markings can occur with the same verbs. A free productivity task was conducted with 100 Sinhalese native speakers living in Sri Lanka. A comparison study was carried out using sentences with the verbs accompanying / wa/ accusatives and $/ \mathrm{ta} /$ accusatives. The results showed that, verbs accompanied by /wa/ case marker and verbs accompanied by /ta/ case marker are incongruent. Thus, this study concluded that Sinhalese active sentences consisting of transitive verbs are broadly divided into two patterns; those which take only /wa/ accusatives and those which take only /ta/ accusatives.
\end{abstract}

Index Terms - Sinhalese language, active sentences, transitive verbs, /wa/ accusatives, /ta/ accusatives

\section{INTRODUCTION}

Sinhalese (also referred to as Sinhala, Singhala and Singhalese, (Englebretson \& Carol, 2005)) is one of the major languages spoken in Sri Lanka. The history of Sinhalese goes back to two thousand years ago and more (Herath, et al., 1994). Its word order is said to be in the form of subject (S) object (O) and verb (V) (Dissanayaka, 2007; Pallatthara \& Weihene, 1966). Sinhalese has two distinctive forms: the written form and the spoken form. These two forms differ noticeably in their core grammatical structures (Englebretson \& Carol, 2005; Miyagishi, 2005). Subject-verb agreement, for instance, can be pointed out as a main difference between the spoken and the written forms. In the written form, the subject must agree with the verb in gender (male/ female), number (singular/ plural) and person $\left(1^{\text {st }} / 2^{\text {nd }} / 3^{\text {rd }}\right)$ in order to make a grammatically correct sentence. The spoken form, however, does not require subject-verb agreement in that only one form of the verb can be used for all gender, number and persons. For example, an English sentence 'Nimal hit Kamal' in Sinhalese can have different morphological inflections on the verb such as nimal kamala-ta gehuwa (spoken) and nimal kamala-ta gehuweaya (written). The spoken form is mostly used in daily life and other kind of casual communication, whereas the written form is used for official purposes such as materials written on news papers and other formal documents. While the spoken form is very flexible in various syntactic aspects, the written form involves many grammatical rules (Dissanayaka, 2007). Although Sinhalese distinguishes many features from Indo Aryan languages, it also possesses some common features shared by other languages. Animacy, for instance, has been reported as a salient category in Indo-Aryan languages, and it also plays an important role in Sinhalese syntactic and semantic categories (Carmen, 2006; Garland, 2006; Henderson, 2006). In addition, comparative studies on Sinhalese (Noguchi, 1984; Miyagishi, 2003, 2005) have also reported that animacy playing a rather salient and unique role from the phrase level to sentence level. Usage of postpositions, for example, is said to be influenced by the animacy involvement (Chandralal, 2010; Dissanayaka, 2007).

Although Sinhalese possesses many postpositions, not all the nouns can be accompanied with them. A case in point, in active sentences, if the direct object is an animate noun, it always accompanies a postpositional marker to denote the case despite the nature of verbs as in kamal niila-ta gehuwa[ $\varphi \mathrm{NOM}$, anim [ACC, anim [V+PST]]] meaning 'Kamal hit

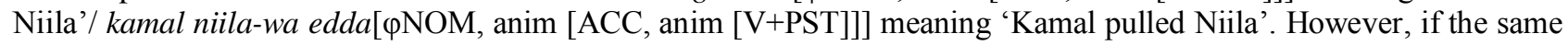
position (ACC) is replaced by an inanimate noun, it may be denoted by a postpositional marker depending on the verb; kamal measaya gattha $[\varphi \mathrm{NOM}$, anim [ $\varphi \mathrm{ACC}$, inam [V+PST]]] meaning 'Kamal bought a table' / kamal measaya-ta gehuwa $[\varphi \mathrm{NOM}$, anim [ACC, inam [V+PST]]] meaning 'Kamal hit the table'. Accordingly, it is clear that the role of animacy is rather crucial in Sinhalese syntax. This study is focused on animate nouns which evidently have a complex usage with relation to case markings.

A previous study done by Aisen (2003), has proposed that Sinhalese is a language where a phenomenon called DOM (differential object markings) exists. According to this proposal, Sinhalese direct objects (i.e., animate nouns) can be marked by two different case markers to denote the accusative case. Although this study has proposed the usage of 
differential case markings in Sinhalese, it has not given further evidence on the verbs accompanied with them. The examples in the previous paragraph are evidential for the fact that, although the same animate noun can be subjected to the afore mentioned phenomenon, it is possible that these markers are accompanied by different verbs. Therefore, this study investigated this complex usage of two case markers of the Sinhalese language in active sentences consisting of transitive verbs.

In the following sections, I shall start with a brief description about the Sinhalese sentences types and case markings. Previous studies (Dissanayaka, 2007; Gunasekara 1999) have provided different categorizations of Sinhalese sentences both in semantic and syntactic perspectives which evidently have provided ample evidence on many complexities of Sinhalese sentences. However, since this study is only focused on simple sentences in the active voice, this section will categorize Sinhalese active sentences into a rather simple and argument based categorization. It is assumed that the present categorization might mask the potential complexities in the syntax, though, is not a significant factor for the later discussion. In addition, this section will also provide detailed information on the usage of case markers. Section 3 will discuss the nature of the DOM (Differential Object Markings) phenomenon with its uniqueness in the Sinhalese language in relation to the animacy involvement. Section 4 will deal with the data obtained from the native Sinhalese speakers and further categorize the verbs used in $/ \mathrm{wa} /$ and $/ \mathrm{ta} /$ accusatives. Finally, section 5 will provide an overall view of the $D O M$ phenomenon in the Sinhalese language.

\section{Sentence Types And Noun Phrase CASes in Sinhalese}

\section{A. Sentence Categorization and Syntactic Structure}

As any other language in the world, Sinhalese also comprises different categories to mark different parts of the language such as nouns, verbs, sentences, etc. According to Gunasekara (1999), Sinhalese nouns are classified into two principle classes as common nouns and proper nouns, whereas, verbs are also classified into two principle classes; transitive verbs and intransitive verbs. Sentences, on the other hand, are divided into six kinds; Simple Sentences, Complex Sentences, Contracted Sentences, Collateral Sentences, Compound Sentences and Elliptical Sentences. This categorization involves both semantic and syntactic aspects in wide range. This study however, is focused only on the simple sentences in the active voice. Although Gunasekara (1999) has divided verbs into two basic classes (transitive and intransitive), this paper assumes that there should be another class to classify these verbs as analyzed below. Taking a view based on the predicate and its arguments Carnie (2007) has categorized sentences in terms of noun phrases (NPs) and prepositional phrases (PPs) for English. Although Sinhalese does not share the identical phrases as such in English, it is assumed that the same categorization can also be applied. According to this categorization, verbs in active sentences can be categorized into three patterns which in turn includes the two types mentioned in Gunasekara (1999) and one extra (the ditransitive verbs). Consider the examples below.

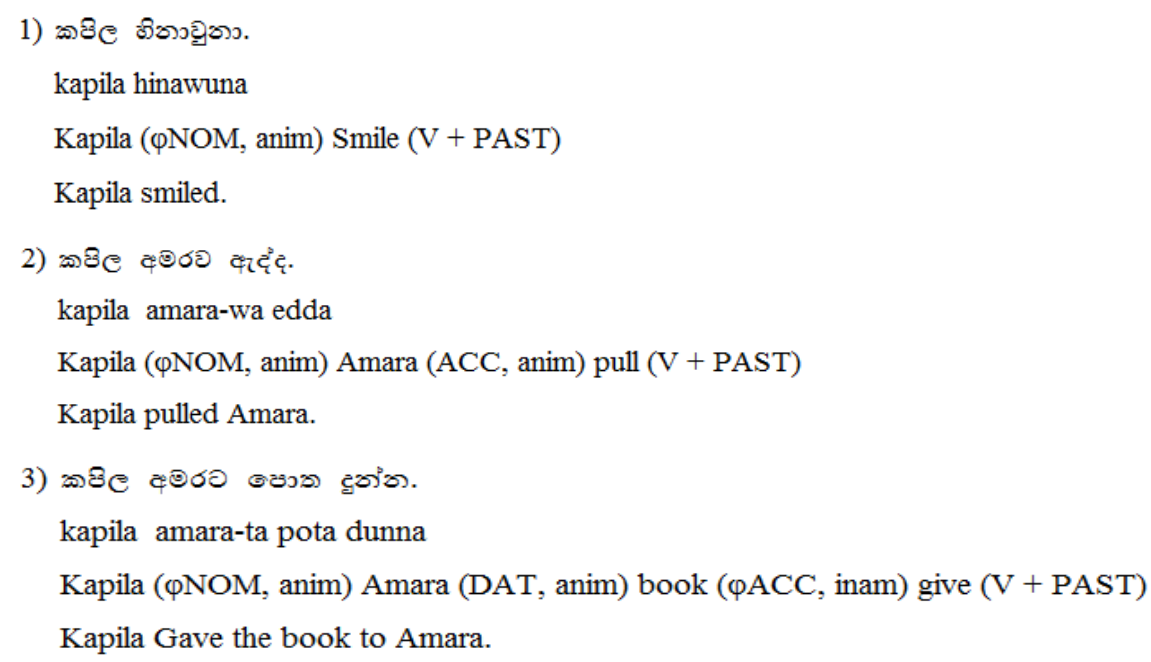

The counterpart of English prepositional phrases in Sinhalese is postpositional phrases (Dissanayaka, 2007). Examples 1), 2), and 3) are active sentences. Example 1) is an active sentence consisting of an intransitive verb. The verb 'smiled (hinawuna)' requires only one obligatory argument kapila [NP $\varphi$ NOM]. 2) Exemplifies an active sentence consisting of a transitive verb where two obligatory arguments are required. The verb 'pulled (edda)' in Sinhalese language requires two NPs as agent kapila and patient amara [ $\varphi \mathrm{NOM}$ and ACC]. Finally, the active sentence in 3) exemplifies a ditransitive verb which in turn requires three arguments. The verb 'gave (dunna)' in Sinhalese language requires three NP arguments. First, the agent kapila $[\varphi \mathrm{NOM}]$ precedes the patient amara-ta [DAT]. Then the theme pota $[\varphi \mathrm{ACC}]$ is placed before the verb dunna. These three types constitute three different hierarchical structures as illustrated in figure 1,2 and 3. 


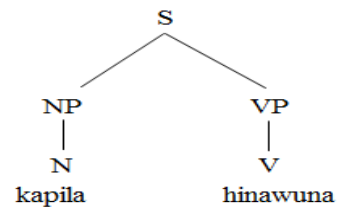

Figure 1. active sentence consisting of an intransitive verb

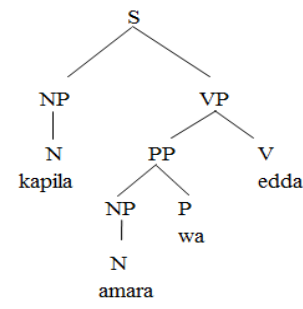

Figure 2. active sentence consisting of a transitive verb

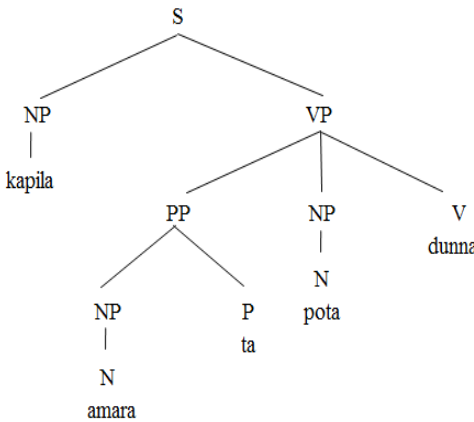

Figure 3. active sentence consisting of a ditransitive verb

\section{B. Noun Phrase Cases in Sinhalese}

Sinhalese has a set of words called postpositions which are divided into eight different classes namely, case particles, predicate particles, highlighting particles, conjunctive particles, discourse particles, interrogative particles, quotative particles, and negative particles (Chandralal, 2010). It is assumed that these eight categories are based on either syntactic (e.g., case particles, predicate particles etc.) or semantic functions (discourse particles, negative particles etc.). However, this study divides Sinhalese postpositions into four main categories; case markers, case inflections, articles and particles. Sinhalese noun phrases are marked by two different parts; case markers or case inflections. Case markers are suffixes (as exemplified in 5) whereas case inflections are infixes (as exemplified in 6). Example 5 indicates a usage of case marker -wa (samara-wa), while example 6 indicates a usage of an inflectional marker -ee (thappaya $+e e=$ thappayee). Accordingly, the main difference between case markers and case inflection is whether the case marked noun undergoes a morphological inflection or not. However, despite the morphological difference, both case markers and case inflections are used to denote the case in Sinhalese. Articles, on the other hand, support to define a given noun into definite or indefinite categories. The rest I categorize as particles. It should be noted that postpositions (as the name itself suggests) occur only at the end of nouns (either inside the NP as a morphological inflection or outside the NP). This study focuses on the usage of Sinhalese case markings. Sinhalese basically marks seven noun phrases; nominative (NOM), accusative (ACC), dative (DAT), genitive (GEN), locative (LOC), instrumental (INSTL) and ablative (ABL) (Garland, 2006). However, not all of them are accompanied with a case marker or case inflection to denote the properties (Noguchi, 1984).

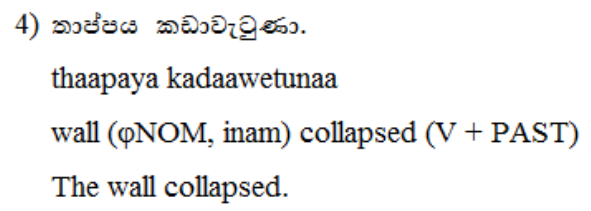

Example 4) illustrates an active sentence consisting of an intransitive verb 'collapsed (kadaawetuna)'. The syntactic structure [NP $\varphi \mathrm{NOM}$, inam [vp V+PAST]] indicates that the nominative element is empty $(\varphi \mathrm{NOM})$. In other words, the nominate case is not denoted by a case marker or an inflectional marker. Recall that, example 1) also carries the identical structure of [NP $\varphi \mathrm{NOM}$, anim [vp V+PAST]]. Despite animacy (as a factor), both sentences show similarity of empty nominative case in active sentences consisting of intransitive verbs. Note that all the examples from 5) to 10) are 
congruent in this regard. The nominative NP is not denoted by a case marker or an inflectional marker. Thus, it is evidential that active sentences consisting of either transitive or intransitive verbs in Sinhalese mark the nominative NP as empty despite the noun properties (namely, animate or inanimate).

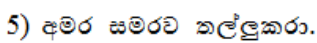

amara samara-wa thallukara

Amara ( $\varphi$ NOM, anim) Samara (ACC, anim) push (V + PAST)

Amara pished Samara.

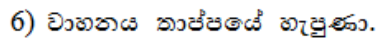

wahanaya thappaye hepuna

vehicle ( $\varphi$ NOM, anim) wall (LOC, inam) hit (V + PAST)

The vehicle hit the wall.

The accusative marked noun 'Samara' in example 5) is denoted by the case marker /wa/, while in 6) the locative marked noun 'wall' is accompanied by an inflectional marker -ee (thappaya $+e e=$ thappayee $)$. Example 7) illustrates the usage of the dative case marker /ta/ with the noun 'Amara', while in example 8) the genitive case marker /ge/ is placed soon after the genitive noun 'Niila'. Finally, in example 9) the instrumental noun 'pencil' is marked by an inflectional marker -en (pensala + en = pensalen), while in 10) the ablative marked noun 'Samara' is accompanied by the ablative marker - gen.

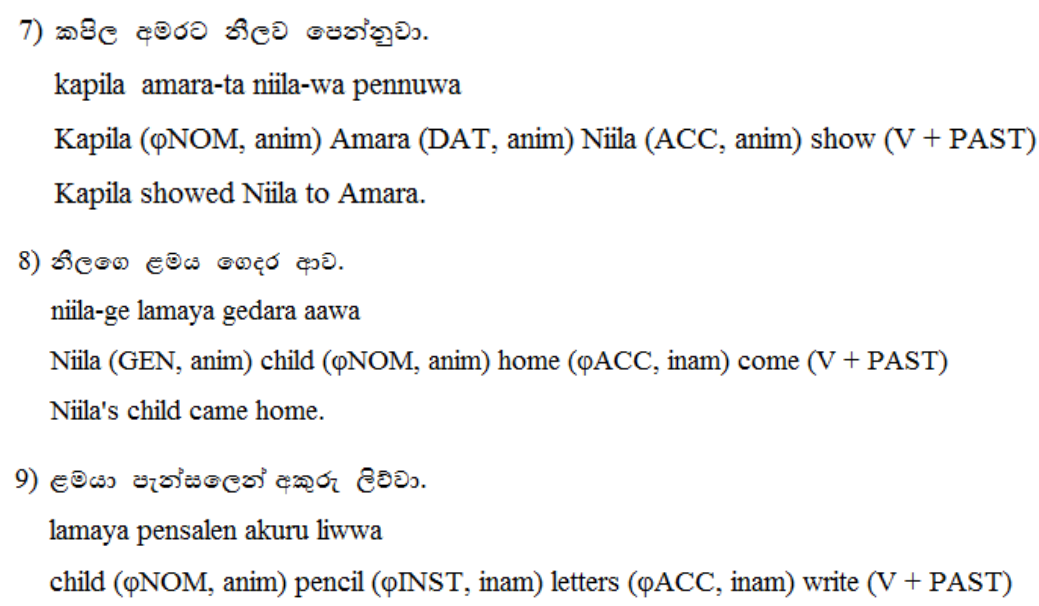

The child wrote letter with pencil.

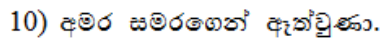

amara samara-gen eethwuna

Amara ( $\varphi$ NOM, anim) Samara (ABL, anim) apart (V + PAST)

Amara apated Samara.

There are two major points on the Sinhalese case markings. One, it is evidential that noun phrase cases are not only marked by case markers (suffixes), but also by case inflections (infixes). Second, as previous studies also suggest (Miyagishi 2003; Noguchi, 1984) the nominative NP is always marked empty regardless of the animacy (animate or inanimate). Furthermore, there is also another different usage of case markers especially where animacy is factored. The next section will elaborate this usage in-depth.

\section{DuAL NATURE OF DOM PHENOMENON}

The previous section explained that the Sinhalese dative marked nouns are denoted by the case marker /tal. However, according to some studies (Miyagishi, 2003, 2005; Noguchi, 1984), the dative /ta/ is not used only to mark the dative element in the Sinhalese sentences. It also has another usage in active sentences consisting of transitive verbs. Consider the examples below.

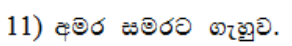

amara samara-ta gehuwa

Amara ( $\varphi$ NOM, anim) Samara (ACC, anim) hit (V + PAST)

Amara hit Samara. 


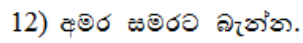

amara samara-ta benna

Amara ( $\varphi \mathrm{NOM}$, anim) Samara (ACC, anim) scold (V + PAST)

Amara scolded Samara.

Both 11) and 12) are active sentences consisting of transitive verbs. The syntactic structures of both sentences are identical [NP $\varphi \mathrm{NOM}[\mathrm{vP}$ ACC [V+PAST]]]. It is evident that the usage of dative case marker /ta/ is somewhat different from the $/ \mathrm{ta} /$ mentioned in the previous section. That is, / ta/ is used to denote the dative elements (in active sentences consisting of ditransitive verbs as exemplified in 7). However, here /ta/ is also used to denote the accusative elements in the same regard, which in turn suggest that the Sinhalese language possesses two different markers to denote accusative cases (/wa/ and /ta/). A previous study conducted by Aisen (2003) proposes that Sinhalese is a language where DOM (Differential Object Marking) can be noticeable in active sentences. For example, the accusative marked nouns (i.e., direct objects) in active sentences consisting of transitive verbs can have two different case markers depending on the animacy of given nouns. On one hand, accusative marked nouns (only animate objects) can be denoted by the accusative case marker $/ \mathrm{wa} /$. On the other hand, the same nouns can also be denoted by the dative case marker /tal (compare example 5 and 11).

The DOM phenomenon in Sinhalese is unique in three aspects. First, it can only be seen in active sentences consisting of transitive verbs. Note that in the other two types mentioned in section 2.1 (active sentences consisting either intransitive or ditransitive verbs), we do not see this phenomenon. In active sentences consisting of intransitive verbs usually do not accompany case markers as only one argument is required ( $\varphi \mathrm{NOM}-\mathrm{V})$, while active sentences consisting of ditransitive verbs always require three arguments ( $\varphi$ NOM-DAT-ACC-V). Second, the phenomenon can be seen only with the accusative marked nouns (i.e., accusative cases), but not with any other cases mentioned in the previous section. Third, the phenomenon only exists in sentences where an animate noun is placed in the accusative position. It should be noted that, when an inanimate noun is used in the accusative position, only /ta/ is used as a case marker (e.g., 13). If /wa/ is used after inanimate accusative noun, the sentence is considered grammatically ill-formed as depicted in 14).

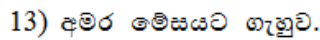

amara measaya-ta gehuwa

Amara ( $\varphi$ NOM, anim) table (ACC, inam) hit (V + PAST)

Amara hit the table.

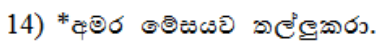

amara measaya-wa thallukara

Amara ( $\varphi$ NOM, anim) measaya (ACC, inam) push (V + PAST)

Amara pushed the table.

Example 14) is derived from example 5). Besides animacy, both 13) and 14) fundamentally carry the identical structure of [NP $\varphi \mathrm{NOM}[\mathrm{vP}$ ACC [V+PAST]]]. However, 14) is considered grammatically ill-formed since / wa/ is placed after the inanimate accusative marked noun. In Sinhalese, these nouns are used with either /tal; amara measaya-ta gehuwa [NP $\varphi \mathrm{NOM}$, anim [VP ACC, inam [V+PAST]] 'Amara hit the table' or, without a case marker; amara measaya thallukara [NP $\varphi \mathrm{NOM}$, anim [vP $\varphi \mathrm{ACC}$, inam [V+PAST]]] 'Amara pushed the table'.

\section{IV. /Wa/ AcCuSATIVES Vs. /TA/ ACCUSATIVES in SinHaLeSE}

Since the DOM suggests Sinhalese has two different markers to denote the accusative nouns, it is assumed that accusative cases in Sinhalese can be divided into two types; / wa/ accusatives and /ta/ accusatives. Thus, these accusatives may accompany different verbs. Therefore, this study conducted a survey in order to investigate whether the verbs are identical in both patterns.

\section{A. Data Collection}

The data was collected from 100 high school students (57 females and 43 males) staying in Colombo, Sri Lanka (average age been 16 years and 3 months). A free productivity task ${ }^{1}$ was done to collect the data. Participants were asked to write 20 active sentences consisting of transitive verbs using / wa/ and /ta/ case markers (10 of each). Overall, 2000 sentences (1000 each) were collected.

\footnotetext{
${ }^{1}$ In this task, the participants were asked to write active sentences consisting of transitive verbs, thus the sentences were in the form of Subject+ Object+ Verb.
} 


\section{B. Analysis and Results}

Sentences in both accusative types were analyzed separately. All the verbs used in /wa/ accusatives and /tal accusatives are presented in appendixes A, B, C, and D (not that English gloss is presented in the present tense, whilst Sinhalese is presented in the past tense). These appendixes are organized according to the descending order of the occurring frequency. Number of verbs and their occurring frequency is presented in table 1.

\begin{tabular}{|c|c|c|c|c|}
\hline & $/ w a /$ accusatives & Frequency & $/ \mathrm{ta} /$ accusatives & Frequency \\
\hline Simple verbs & 16 & 0.37 & 13 & 0.35 \\
\hline Compound verbs & 30 & 0.50 & 25 & 0.54 \\
\hline Extra verbs & 5 & 0.13 & 5 & 0.11 \\
\hline Total & 71 & 1.00 & 43 & 1.00 \\
\hline
\end{tabular}

The analysis showed that verbs used in both patterns are not identical (despite extra 5 verbs). A total of 46 different verbs were found in / wa/ accusatives, whereas, /ta/ accusatives were used with a total of 38 verbs. Both patterns showed to have two basic types of verbs; simple verbs and compound verbs as shown in table 1 . In the sentences where /wa/ accusatives are accompanied with verbs, there were 16 simple verbs; whilst in the sentences where /ta/ accusatives are accompanied had only 13 simple verbs. Compound verbs, on the other hand, again subcategorized into different types according to the root verbs. However, both accusatives had same number of coumpound verb types (10 each), /wa/ accusatives; gattha, kala, giya, geawa, gehuwa, heriya, benda, keawa, keawa, dunna, demma: Ital accusatives; kala, gehuwa, pethuwa, thibba, dunna, kiwwa, desuwa, benda, beawa, elluwa. Gunasekara (1999) has given two basic categorizations for the Sinhalese compound verbs; those which composed of Elu words (verbs of Sinhalese origin) only $\&$ those made up by imported words and an Elu word (the more extensive class). The compound verb types found in the present study included both classes. Previous studies (Englebretson \& Carol, 2005; Gunasekara, 1999) also suggest that Sinhalese verb morphology is complex, in that it consists of a number of inflectional classes. According to Dissanayaka (2008), Sinhalese verbs have four kinds of morphological inflections; ' $a$ ' type [ $\square$ ], ' $i$ ' type [i], ' $e$ ' type [e], and 'exclusive' type which the rest of all are included. In written Sinhalese, verbs usually undergo morphological inflections for tense, person, number and voice. However, this study is conducted with the spoken form of Sinhalese language. As mentioned in the introduction, the morphological inflections of the spoken form of verbs are less distinctive since the same form of a verb can be used for the number, person and gender. Nevertheless, all the verbs used in the present study were in the past tense. Thus, they all belong to the first type inflections ' $a$ ' (i.e., $k a l+a=k a l a$, $k i w+a=k i w w a$, $d u n+$ $a=$ dunna etc).

\section{Cluster classification on the usage}

Since different types of verbs were involved in both accusatives, a cluster analysis was conducted using dendrograms. Figure 4 represents 3 clusters for the simple verbs used with /tal accusatives (a total of 13 verbs). According to the descending order of the usage, cluster 3 shows $17.20 \%$ usage, whilst cluster 2 shows $12.80 \%$ usage. Finally, cluster 1 shows $4.80 \%$ usage. Based on this result, verbs in cluster 3, 2 and 1 can be considered the high ( 3 verbs), middle (6 verbs) and low (4 verbs) usage with /ta/ accusatives. Also figure 4.1 represents 3 clusters for the compound verbs used with /tal accusatives (a total of 25 verbs). According to the descending order of the usage, cluster 3 shows $24.70 \%$ usage, whilst cluster 1 shows $16.60 \%$ usage. Finally, cluster 2 shows $13.10 \%$ usage. Based on this result, verbs in cluster 3, 1 and 2 can be considered the high ( 9 verbs), middle (13 verbs) and low (3 verbs) usage with /ta/ accusatives.

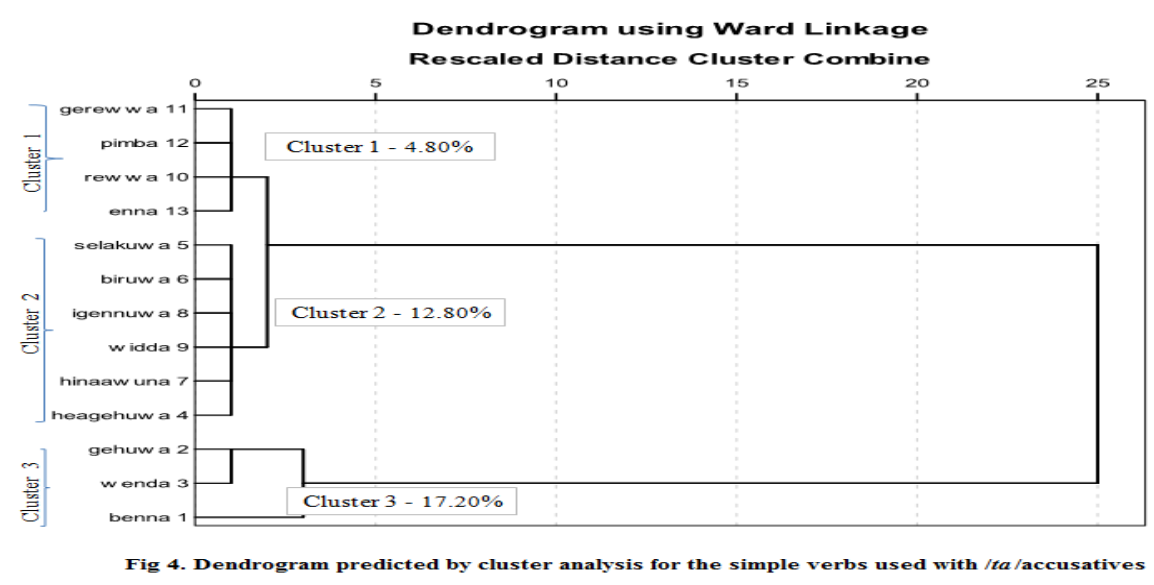




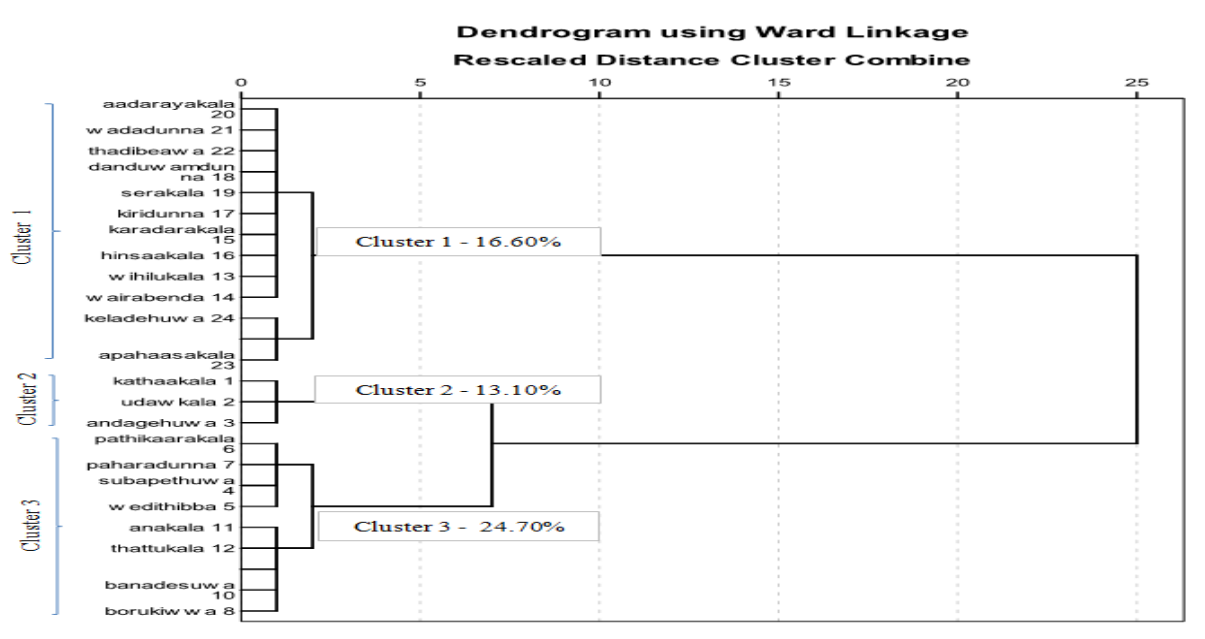

Following, figure 5 represents 3 clusters for the simple verbs used with /wa/ accusatives (a total of 16 verbs). According to the descending order of the usage, cluster 3 shows $23.30 \%$ usage, whilst cluster 2 shows $10.30 \%$ usage. Finally, cluster 1 shows $3.30 \%$ usage. Based on this result, verbs in cluster 3, 2 and 1 can be considered the high (6 verbs), middle (5 verbs) and low (5 verbs) usage with / wa/ accusatives.

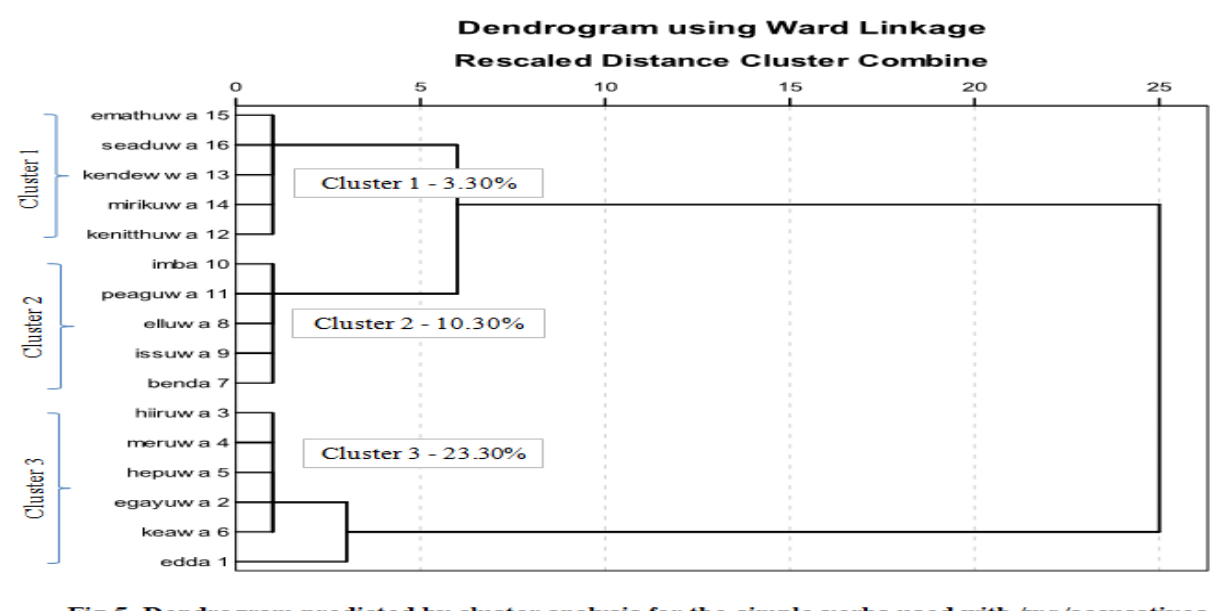

Lastly, figure 5.1 represents 4 clusters for the compound verbs used with /wa/ accusatives (a total of 30 verbs). The descending order according to the usage is, cluster 4 (18.40\% usage), cluster 2 (16.60\% usage), cluster 3 (12.20\% usage) and cluster 4 (2.80\% usage). Based on this result, verbs in cluster 4, 3, 2 and 1 can be considered as the high (5 verbs), middle (13 verbs), lower middle (6 verbs), and low (6 verbs) usage with /wa/ accusatives. 


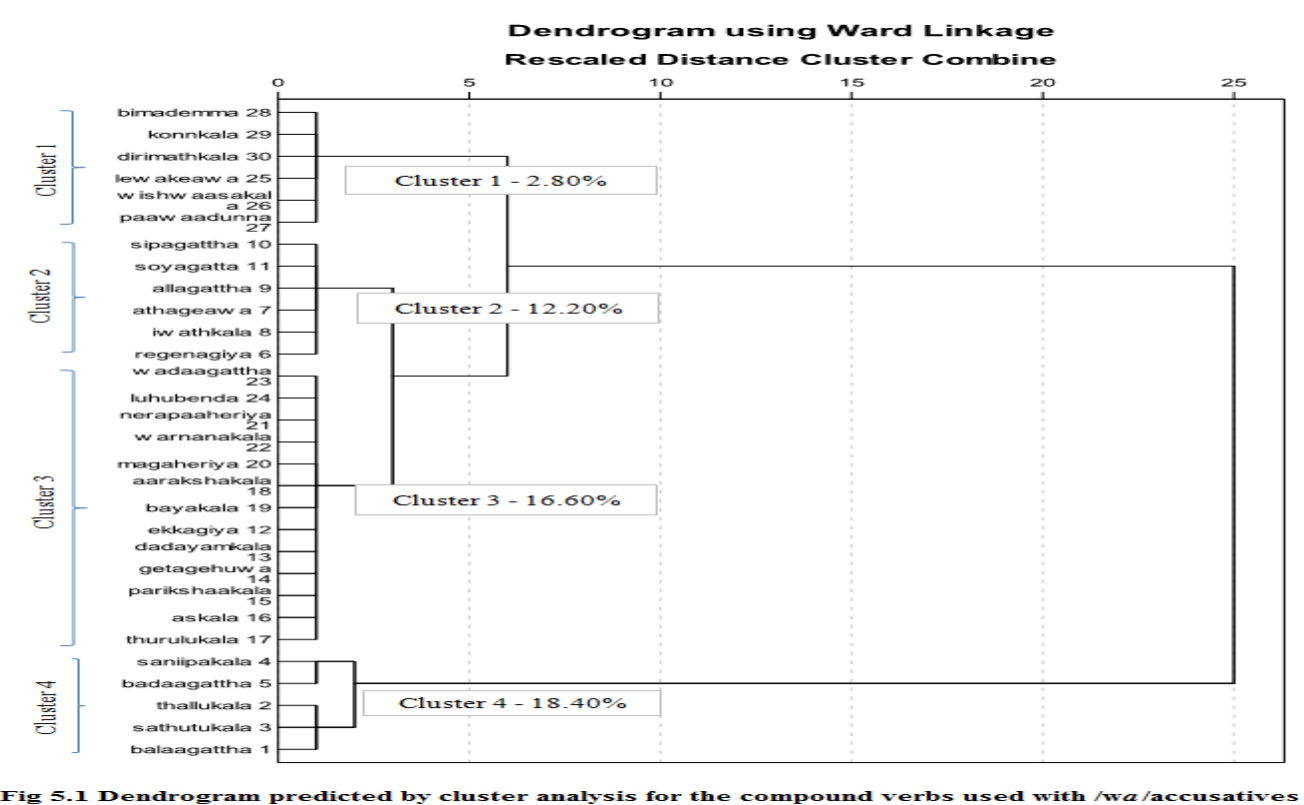

Note that, all the verbs classified into clusters do not always match with the descending order of the usage. Furthermore, both $/ \mathrm{wa} /$ and $/ \mathrm{tal}$ accusatives consisted of some compound verbs where the root verbs are identical, in that 4 root verbs happen to occur in both patterns. For example, gehuwa as in sunil kamal-ta andagehuwa (Sunil called Kamal) versus sunil kamal-wa pelagehuwa (Sunil lined Kamal), kalaa as in sunil kamal-ta kathaakala (Sunil summoned Kamal) versus sunil kamal-wa konkala (Sunil ignored Kamal), dunna as in sunil kamal-ta athadunna (Sunil helped Kamal) versus sunil kamal-wa adunnaladunna (Sunil introduced Kamal) and benda as in sunil kamal-wa benda (Sunil tied Kamal) versus sunil kamal-ta wairabenda (Sunil hated Kaml). Note that although these root verbs are identical, when they are used with additional parts (nouns or adjectives) these verbs vary in meaning, and are considered not a significant factor to be considered in the same class.

The present analysis showed that Sinhalese active sentences consisting of transitive verbs can be categorized into two classes; verbs accompany case marker / wa/ and verbs accompany the case marker /ta/ in order to denote the accusative case in the same regard. Furthermore, according to the verbs used in the production task, the traditional accusative marker / wa/ showed rather high usage compared to the traditional dative marker /tal. However, there were some five exceptional verbs which being used in both accusative types. One simple verb (-wa /ta ridduwa root meaning of 'hurt') and four compound verbs (-wa/ta tharawatukala root meaning of 'reprimand', -wa/ta thuwaalakala root meaning of 'hurt', -wa/ta dashtakala root meaning of 'bit', -wa/ta pashanshakala root meaning of 'praise') showed complexity in the usage by native speakers. These verbs may need further investigation in order to clarify the hidden significance of the usage.

\section{CONCLUSION}

The present study conducted a survey analysis on the usage of two case markers in Sinhalese sentences; accusative /wa/ and dative /tal. According to Aisen, (2003) and Kanduboda, (2011), Sinhalese is a language with differential object markings, meaning that the accusative nouns in the active sentences can have two different markers (/wa/ or /ta/), on the condition of animate nouns. However, the verbs were not taken into account in the previous studies. Although the same accusative noun (i.e., direct object) can take two different markers, the accompanying verbs can be different. Therefore, an investigation was conducted to observe whether / wa/ accusatives and /ta/ accusatives`are accompanied by identical verbs.

In this study, Sinhalese active sentences were categorized into three types; active sentences consisting of intransitive verbs, active sentences consisting of transitive verbs and active sentences consisting of ditransitive verbs. Noun phrases in intransitive sentences usually do not accompany case markers (patterns concerned in this study). Ditransitive sentences, on the other hand, require three arguments (nominative, dative and accusative). Thus, in these sentences dative case marker does not occur twice in the same context. However, transitive sentences remain doubtful leaving a possibility for the DOM phenomenon. Furthermore, albeit Sinhalese possesses a number of case markers, only dative case marker appear to have a complex usage especially in active sentences where an accusative element is presented with an animate noun. Therefore, first, active sentences with transitive verbs were observed with the dual nature of DOM phenomenon. As suggested in the previous studies (Aisen, 2003), the data reconfirmed that animacy is a salient factor; only animate nouns in the accusative case may take two case markers where as inanimate nouns are either accompanied by the dative case marker /ta/ or left empty. 
The data (verbs) collected from the native speakers were analyzed in two arrays; verbs accompanying /wa/ and verbs accompanying /ta/. First, the verbs in both types were categorized into two basic classes; simple verbs and compound verbs. The simple verbs showed that they occur in one pattern, either /wa/ or /ta/. Although some types of compound verbs in both patterns were identical (they both end with the same root verbs), the nouns and the verbs adjoining them were different (refer to appendix C \& D). Thus, the meaning and the usage are considered to be different. The overall picture of the Sinhalese DOM phenomenon is depicted in figure 6. Previous studies have claimed up to $3^{\text {rd }}$ point (left side of the figure) on the usage of differential object markers in Sinhalese language. However, a detailed study has not been carried out since then. Thus, this study conducted further two parts (number $4 \& 5$ ) in order to reveal the remaining of this phenomenon. According to this study, active sentences consisting of transitive verbs (both simple and compound) in the Sinhalese language can be divided into two basic patterns; verbs which take only /wa/ accusatives and verbs which take only /ta/ accusatives. However, there were five other exceptional examples which this study does not cover. These four verbs remain doubtful as they occurred with both / wa/ and /ta/ accusatives. Hence, a further survey would be necessary to explore the cause of these hidden factors in the Sinhalese language.

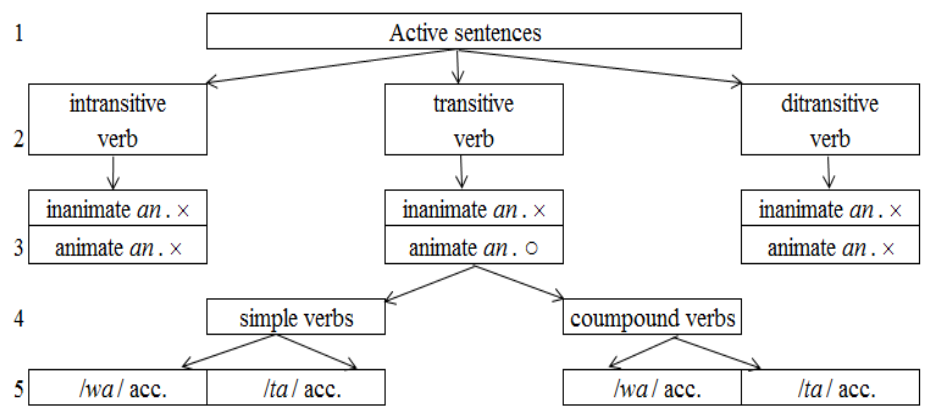

Figure 6. Overall of $D O M$ in the Sinhalese Sentences

Note: an. referes to accusative noun

acc. referes to accusative marker

○ shows the situation where $D O M$ exists

$\times$ shows the the situations where DOM does not exist

Appendix A. Simple verbs used in $/ w a /$ accusatives

\begin{tabular}{|c|c|c|c|}
\hline & Sinhalese & Pronounciation & Gloss \\
\hline 1 & વَંदُุद & edda & Pull \\
\hline 2 & $q \xi(\omega) \Leftrightarrow$ & egayuwa & Praise \\
\hline 3 & कిర్య & hïlwwa & Scratch \\
\hline 4 & $0,6,0$ & meruwa & Kill \\
\hline 5 & 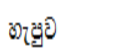 & hepuwa & Bit \\
\hline 6 & 田? & keawa & Eat \\
\hline 7 & $\left.\hat{\theta}_{2} \sigma\right)^{\prime} \dot{c}$ & benda & Tie/Marry \\
\hline 8 & વૃદę & elluwa & Catch \\
\hline 9 & จูผืผผูอ & issuwa & Lift \\
\hline 10 & จูฮิล & imba & Kiss \\
\hline 11 & ऊฒ0 & peaguwa & Trample \\
\hline 12 & ๑றธิต่อ & kenitthuwa & Hitch \\
\hline 13 & Фีఠदุอ & kendewwa & Call upon \\
\hline 14 & ฮิ8ฌูอ & mirkkuwa & Grasp \\
\hline 15 & 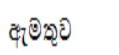 & emathuwa & Call \\
\hline 16 & ๑బ้นู่อ & seaduwa & Wash \\
\hline
\end{tabular}


Appendix B. Simple verbs used in /ta / accusatives

\begin{tabular}{|c|c|c|c|}
\hline & Sinhalese & Pronounciation & Gloss \\
\hline 1 & केणिएक & bentila & Scold \\
\hline 2 & (9) & geluwa & Hit \\
\hline 3 & $\partial x^{\prime}$ & wenda & Worship \\
\hline 4 & 周[1 (9) & heagehuwa & Scream \\
\hline 5 & 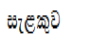 & selakuwa & Host \\
\hline 6 & ลิธน & birnwa & Batk \\
\hline 7 & 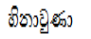 & hinaawuna & Lalugh \\
\hline 8 & 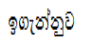 & jgennuwa & Teach \\
\hline 9 & పૈद्ध & widda & Bit \\
\hline 10 & ชออ & rewwa & Stare \\
\hline 11 & ๑0060อ & getewwa & Yawn \\
\hline 12 & 8ำำ & pimba & Blow \\
\hline 13 & $q(0)$ & entilla & Hit \\
\hline
\end{tabular}

Appendix C. Compound verbs used in $/ w a /$ accusatives

\begin{tabular}{|c|c|c|c|}
\hline & Sinhalese & Pronounciation & Gloss \\
\hline 1 & Aि(x) & balaagattha & Take care \\
\hline 2 & 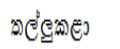 & thallukala & Push \\
\hline 3 & 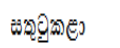 & sathutukala & (Make) happy \\
\hline 4 & జరీతి & saniipakala & Cure \\
\hline 5 & 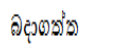 & badaagattha & Hug \\
\hline 6 & வலตڤติติ & regenagiva & Take with \\
\hline 7 & $a n \eta^{2}$ & athageawa & Stroke \\
\hline 8 & ग & iwathkala & Clean/Sack \\
\hline 9 & $a c(e x)$ & allagattha & Catch \\
\hline 10 & 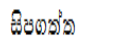 & sipagattha & Kiss \\
\hline 11 & ఆబิว(ติ)(ตร)่า & soyagatta & Find \\
\hline 12 & 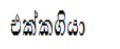 & ekkagiya & Take (with) \\
\hline 13 & 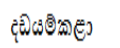 & dadayamkala & Hunt \\
\hline 14 & 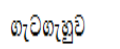 & getagehuwa & Tie \\
\hline 15 & נم8 & parikshaakala & Check \\
\hline 16 & วี & askala & Sack \\
\hline 17 & 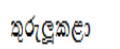 & thunulukala & Warm \\
\hline 18 & כ & aarakshakala & Protect \\
\hline 19 & כ) & bayakala & Frighten \\
\hline 20 & (3) & magaheriya & Avoid \\
\hline 21 & 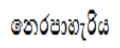 & nerapaaheriya & Sack \\
\hline 22 & נשחه & warnanakala & Prais \\
\hline 23 & อิฆิตร) & wadaagattha & Carry \\
\hline 24 & 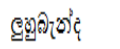 & luhubenda & Chas \\
\hline 25 & ๑ออิมี & lewakeawa & Lick \\
\hline 26 & วิต่อวสตึอ & wishwaasakala & Trust \\
\hline 27 & 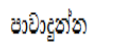 & paawaadunna & Betray \\
\hline 28 & 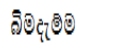 & bimademma & Drop \\
\hline 29 & 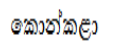 & konnkala & Teas \\
\hline 30 & נק & dirimathkala & Praise \\
\hline
\end{tabular}




\begin{tabular}{|c|c|c|}
\hline Sinhalese & Pronounciation & Gloss \\
\hline 1 काण & kathalada & Call \\
\hline 2 cकmes & udarwkala & Help \\
\hline 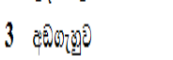 & andagedurwa & call \\
\hline 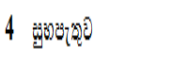 & subapethuxra & Wish \\
\hline 5 ตอบขอ & weditinbba & Shoot \\
\hline 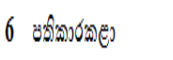 & pattiklkararkala & Treat \\
\hline 7 अəoge & patharaduandana & Hit \\
\hline 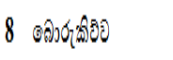 & bonkiswra & Lie \\
\hline 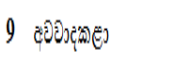 & arravaadakala & Advise \\
\hline 10 ลชช & banadesuwa & Doctine \\
\hline 11 (क人) & ankakala & Order \\
\hline 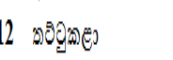 & thatukala & Tap \\
\hline 13 วิธีตख & witilikala & Joke \\
\hline $14008008(5)\}$ & wairabenda & Hate \\
\hline 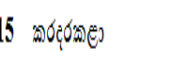 & Karardarackala & Disturto \\
\hline 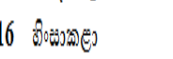 & linssalala & Hut \\
\hline 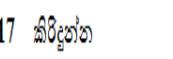 & kiididuma & Milik \\
\hline 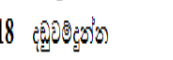 & dandurvamamduna & Punish \\
\hline 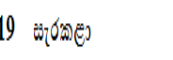 & seratala & Vident \\
\hline 20 केट & aadarayaykala & Love \\
\hline 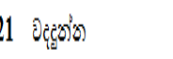 & waddanuma & Punishfrebuke \\
\hline 22 วผิดี & thadibearva & Hitt \\
\hline 23 саш) & apahasascakala & Embarrass \\
\hline 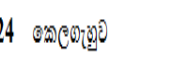 & Keladeluwa & Spit \\
\hline 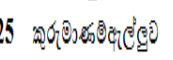 & Lurumananamelluwa & Target \\
\hline
\end{tabular}

\section{REFERENCES}

[1] Aisen, J. (2003). "Differential object marking: Iconicity vs. economy." Natural Language \& Linguistic Theory. 21: 435-483.

[2] Carmen, J. (2006). “The Relationship Between Case Marking and S, A, and O in Spoken Sinhala.” In Englebretson, R. and C. Genetti, eds. Santa Barbara papers in linguistics: proceeding from the workshop on Sinhala linguistics. Santa Barbara, CA: Department of Linguistics at the University of California, Santa Barbara.

[3] Carnie, A. (2007). Syntax. Oxford: Blackwell Publishing.

[4] Chandralal, D. (2010). Sinhala. Amsterdam: John Benjamin's Publishing Company

[5] Dissanayaka, B. J. (2007). Say it in Sinhala. Colombo, Sri Lanka: Stamford Lake Publication.

[6] Dissanayaka, B. J. (2008). Basaka Mahima; Sinhalese Verbs. Colombo, Sri Lanka: Stamford Lake Publication.

[7] Englebretson, R, and Carol, G, eds. (2005). "Santa Barbara papers in linguistics: proceeding from the workshop on Sinhala linguistics." Santa Barbara, CA: Department of Linguistics at the University of California, Santa Barbara.

[8] Garland. J. (2006). "Morphological Typology and the Complexity of Nominal Morphology." In Englebretson, R. and C. Genetti, eds. Santa Barbara papers in linguistics: proceeding from the workshop on Sinhala linguistics. Santa Barbara, CA: Department of Linguistics at the University of California, Santa Barbara.

[9] Gunasekara, M. A. (1999). A Comprehensive of the Sinhalese Language. Madras, New Delhi: Asian Educational Services.

[10] Henderson, M. (2006). "Between Lexical and Lexico-Grammatical Classification: Nominal Classification in Sinhala." In Englebretson, R. and C. Genetti, eds. Santa Barbara papers in linguistics: proceeding from the workshop on Sinhala linguistics. Santa Barbara, CA: Department of Linguistics at the University of California, Santa Barbara.

[11] Herath A., Hyodo Y., Kawada Y., Ikeda, Ti. (1994). "A Practical Machine Translation System from Japanese to Modern Sinhalese", Japan: Gifu University, 153-162.

[12] Kanduboda, A. B. Prabath. (2011). The Role of Animacy in Determining Noun Phrase Cases in the Sinhalese and Japanese Languages, Kotban-no kagaku, Bulletin of the Department of Languages and Cultures, Nagoya University, 24, 5-20. 
[13] Miyagishi, T. (2003). “A Comparison of Word Order between Japanese and Sinhalese.” Bulletin of Japanese Language and Literature, Yasuda Women's University, 33, pp1-8.

[14] Miyagishi, T. (2005). Accusative Subject of Subordinate Clause in Literary Sinhala, Journal of Yasuda Women's University, 33, pp36-47.

[15] Miyagishi, T. (2009) Connection between Accusative Case Marked Nouns and Verbs in Sinhala (1), Journal of Yasuda Women's University, 36, pp 42-51.

[16] Noguchi, T. (1984). Shinhara-go nyuumo. Tokyo: Daigaku Shorin.

[17] Pallatthara, S, and Weihene, P. (1966). Sinhala Grammar in Linguistic Perspective. Colombo, Sri Lanka: S Godage \& Brothers.

Kanduboda A, B. Prabath was born in Colombo Sri Lanka in 1980. The general education from elementary school to high school graduation was attained in D.S. Senanayaka College Sri Lanka. The author obtained his bachelors' degree in social science at Asia Pacific Studies, Ritsumeikan Asia Pacific University, Beppu, Japan in 2005. Following, the author obtained the masters' degree in applied linguistics at Graduate school of Languages \& Cultures, Nagoya University, Nagoya, Japan on 2009. Finally, the author gained the Ph.D. in linguistics at the Graduate school of Languages \& Cultures, Nagoya University, Nagoya, Japan in 2012.

In his working experience, he worked as a part-time lecturer in English both in AichiToho University and Vocational School of Social Service, Nursery, Social Welfare \& International Business, Nagoya, Japan from 2009 to 2013. He now works as a LECTURER in Ritsumeikan University, Ritsumeikan International, Global Gateway Program, Kyoto, Japan. At present the author conducts and is interested in doing research and survey on syntax (Sinhala language), acquisition and competence of English and Japanese as second \& third language, psycholinguistics, academic writing and intercultural communication.

Dr. Kanduboda is a member of Japanese Association of Social Science, The Linguistic Society of Japan, The Japanese Society for Cognitive psychology. 